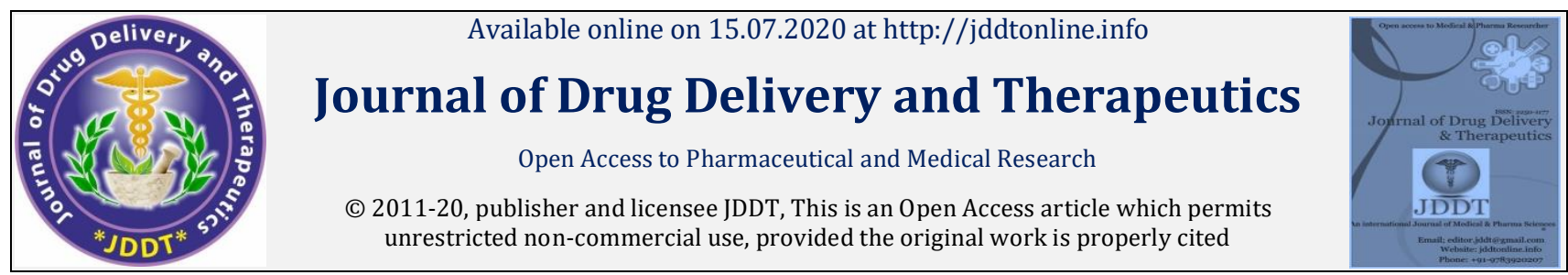

Open 1 Access

Research Article

\title{
Antioxidant and Antimicrobial Activities of Methanolic Leaves Extract of Lagerstroemia parviflora
}

\author{
Namita Bharadwaj ${ }^{1}$, Anjna Chaturvedi ${ }^{2 *}$ \\ ${ }^{1}$ Associate Professor, Dr. C. V. Raman University, Kota Bilaspur, (C.G.), India \\ 2 Research Scholar Ph.D., Chemistry Dr. C. V. Raman University, Kota Bilaspur, (C.G.), India
}

\begin{abstract}
An antioxidant is a molecule capable of terminating the chain reactions that damage cells by removing free radical intermediates and inhibit other oxidation reactions by thereby reducing stress responsible for many degenerative disorders. The present study was concerned with phytochemical screening, antioxidant, antimicrobial activities of methanolic leaves extract of Lagerstroemia parviflora. It was observed that the methanol extract showed IC 50 value of $76.05 \mu \mathrm{g} / \mathrm{ml}$ as compare to standard ascorbic acid $14.66 \mu \mathrm{g} / \mathrm{ml}$. It was evident that the extracts showed proton-donating ability and this could serve as free radical inhibitors or scavengers, acting possibly as primary antioxidants. Thus the methanol extract of this plant possesses the strongest ability to scavenge DPPH radical. The leaves extracts of Lagerstroemia parviflora exhibited potential antibacterial activity against Staphylococcus aureus $(20 \pm 0.2,21 \pm 0.1$ and $23 \pm 0.1)$, Salmonella bongori $(9 \pm 0.3,12 \pm 0.1$ and $15 \pm 0.5)$ and Aspergillus niger $(7 \pm 0.1,9 \pm 0.1$ and $11 \pm 0.2)$ at the concentration level of $25-100 \mathrm{mg} / \mathrm{ml}$. The Results of antimicrobial activity of extract showd more effectiveness against both the selected bacteria (Staphylococcus aureus and Salmonella bongori) found less effective against fungus (Aspergillus niger). The present study suggests that the use of leaves of this plant may be exploited for health supplements and has potential for topical treatment.
\end{abstract}

Keywords: Lagerstroemia parviflora, Antioxidant, Antimicrobial

Article Info: Received 14 April 2020； Review Completed 27 June 2020; Accepted 02 July 2020; Available online 15 July 2020

Cite this article as:

Bharadwaj N, Chaturvedi A, Antioxidant and Antimicrobial Activities of Methanolic Leaves Extract of Lagerstroemia parviflora , Journal of Drug Delivery and Therapeutics. 2020; 10(3-s):206-210

http://dx.doi.org/10.22270/jddt.v10i3-s.4174

*Address for Correspondence:

Anjna Chaturvedi, Research Scholar Ph.D., Chemistry Dr. C. V. Raman University, Kota Bilaspur, (C.G.), India

\section{INTRODUCTION}

The plants with the antioxidant activity have drawn attention in recent years due to the development of a large number of different diseases ${ }^{1,2}$. It has been hypothesized that these diseases are caused by action of free radicals in most cases ${ }^{3}$. Antioxidants have the ability to inhibit the free radicals generation or to remove the already formed free radicals by their direct action 4 . There are a number of natural antioxidants, e.g. $\alpha$-tocopherol5; ascorbic acid 6,7; retinol, thiamin and riboflavin, flavonoids 8 and phenolic acids 5,9 as well as a number of synthetic antioxidants ${ }^{10,11}$. Synthetic antioxidants such as butylated hydroxyanisole (BHA) and butylated hydroxytoluene (BHT) have a potentially harmful effect on human health, leading to various dysfunctions ${ }^{10}$. One of the most important trends in the food and pharmaceutical industry today is searching for natural antioxidants from the plant material. Medicinal plants have been used for centuries as remedies for various diseases because they contain bioactivecomponents of a therapeutic value ${ }^{11-14}$. There is the increasing use of a

ISSN: 2250-1177 traditional medicine as an alternative form for treating various diseases due to the resistance of microorganisms to the existing synthetic antibiotics 13,15 . A large number of studies investigate the antimicrobial activity of natural phenolic compounds from plants,16-19 in order to find new, natural antimicrobial agents. Flavonoids are synthesized in plants in response to microbial infection. It is therefore not surprising that these compounds have in vitro antimicrobial activity against a wide range of microorganisms ${ }^{20,21}$. Some phenolic compounds, such as resveratrol, hydroxytyrosol, quercetin and many phenolic acids may inhibit many pathogenic microorganisms $22-24$. Acne vulgaris is a cutaneous disorder of multifactorial origin which manifests in the pilosebaceous follicle. It is characterized by open and closed comedones and inflammatory lesions like papules, pustules and nodules 25 . Micro-organisms like Propionibacterium acnes, Staphylococcus aureus and Staphylococcus epidermidis proliferate rapidly ${ }^{26}$ leading to the development of acne. In clinical management of acne vulgaris, a considerable number of antibiotics and 
chemotherapeutic agents are available in the global market as topical or systemic treatment modalities ${ }^{27}$. Topical therapy is preferred as first-line treatment in mild acne whereas for moderate and severe type of acne, systemic therapy is required in addition to topical therapy. Topical therapy has associated side effects and the undesirable physicochemical characteristics of certain important agents like tretinoin and benzoyl peroxide affect their utility and patient compliance ${ }^{28}$. The latest treatment regimen followed is the one-step acne solutions 29 , but they too have disadvantages in that, they are $99 \%$ oil based creams and contain either (or both) benzoyl peroxide or (and) salicylic acid. Oil based products are counterproductive because they both fight and contribute to acne by clogging pores. Benzoyl peroxide $^{30}$ and salicylic acid ${ }^{31}$ are generally more irritating than acne itself. So the authors felt a need to develop a formulation that is water based and devoid of harmful chemicals. Herbal therapies on the other hand are gaining attention in comparison to existing formulations which cause enormous side effects like skin dryness, rashes, wrinkling, erythema, pruritis, skin eruption and development of resistance ${ }^{32}$. Thus, the aim of this study is phytochemical analysis, antioxidant and antimicrobial activities of methanolic extract of Lagerstroemia parviflora leaves.

\section{MATERIALS AND METHODS}

Plant material (Leaves) selected for the study were washed thoroughly under running tap water and then were rinsed in distilled water; they were allowed to dry for some time at room temperature. Then the plant material was shade dried without any contamination for about 3 to 4 weeks. Dried plant material was grinded using electronic grinder. Powdered plant material was observed for their colour, odour, taste and texture. Dried plant material was packed in air tight container and stored for phytochemical and biological studies.

\section{Chemical reagents}

All the chemicals used in this study were obtained from $\mathrm{Hi}$ Media Laboratories Pvt. Ltd. (Mumbai, India), Sigma-Aldrich Chemical Co. (Milwaukee, WI, USA), SD Fine-Chem. Ltd. (Mumbai, India) and SRL Pvt. Ltd. (Mumbai, India).All the chemicals and solvent used in this study were of analytical grade. The pathogenic microbes used in the current study were obtained from Microbial Culture collection, National Centre Forcell Science, Pune, Maharashtra, India.

\section{Extraction by maceration process}

$89 \mathrm{gm}$ of dried plant material were extracted with methanol using maceration method for 48 hrs. The extracts were evaporated above their boiling points and stored in an air tight container free from any contamination until it was used. Finally the percentage yields were calculated of the dried extracts.

\section{Phytochemical screening of the extract}

The extract of L. parviflora was subjected to qualitative analysis for the various phytoconstituents like alkaloids, carbohydrates, glycosides, phytosterols, saponins, tannins, proteins, amino acids and flavonoids.

\section{Antioxidant activity (DPPH model) of methanolic extract of Lagerstroemia parviflora (Leaves)}

DPPH scavenging activity was measured by the spectrophotometer [33]. Stock solution $(6 \mathrm{mg}$ in $100 \mathrm{ml}$ methanol) was prepared such that $1.5 \mathrm{ml}$ of it in $1.5 \mathrm{ml}$ of methanol gave an initial absorbance. Decrease in the absorbance in presence of sample extract at different concentration $(10-100 \mu \mathrm{g} / \mathrm{ml})$ was noted after 15 minutes. $1.5 \mathrm{ml}$ of DPPH solution was taken and volume made till $3 \mathrm{ml}$ with methanol, absorbance was taken immediately at 517 $\mathrm{nm}$ for control reading. $1.5 \mathrm{ml}$ of DPPH and $1.5 \mathrm{ml}$ of the test sample of different concentration were put in a series of volumetric flasks and final volume was adjusted to $3 \mathrm{ml}$ with methanol. Three test samples were taken and each processed similarly. Finally the mean was taken. Final decrease in absorbance was noted of DPPH with the sample at different concentration after 15 minutes at $517 \mathrm{~nm}$.

Calculation of \% Reduction

$$
=\frac{\text { Control Absorbance }- \text { Test absorbance }}{\text { Control Absorbance }} \times 100
$$
Antimicrobial activity of methanolic extract of
Lagerstroemia parviflora (Leaves)

\section{Pathogenic Antimicrobial used}

The pathogenic microbes used in the current study obtained from microbial culture collection, national centre forcell science, Pune, Maharashtra, India.

Media preparation (broth and agar media)

Composition of nutrient agar media

\begin{tabular}{|l|l|}
\hline Agar & 1.5 gms. \\
\hline Beef extract & 0.3 gms. \\
\hline Peptone & 0.5 gms. \\
\hline Sodium chloride & 0.55 gms. \\
\hline Distilled water & to make $100 \mathrm{ml}$. \\
\hline $\mathrm{pH}-7$ & \\
\hline
\end{tabular}

Composition of Potato Dextrose Agar media;

\begin{tabular}{|l|l|}
\hline Agar & 2.0 gms. \\
\hline Potato infusion & 20 gms. \\
\hline Dextrose & 2.0 gms. \\
\hline Distilled water & to make $100 \mathrm{ml}$. \\
\hline $\mathrm{pH}-7$ & \\
\hline
\end{tabular}

\section{Method of preparation}

This agar medium was dissolved in distilled water and boiled in conical flask of sufficient capacity. Dry ingredients are transferred to flask containing required quantity of distilled water and heat to dissolve the medium completely. The flask containing medium was cotton plugged and was placed in autoclave for sterilization at $15 \mathrm{lbs} /$ inch $^{2}\left(121^{\circ} \mathrm{C}\right)$ for 15 minutes. After sterilization, the media in flask was immediately poured $(20 \mathrm{ml} /$ plate $)$ into sterile petri dishes on plane surface. The poured plates were left at room temperature to solidify and incubate at $37{ }^{\circ} \mathrm{C}$ overnight to check the sterility of plates. The plates were dried at $50^{\circ} \mathrm{C}$ for 30 minutes before use.

\section{Antibiogram Studies}

Broth cultures of the pure culture isolates of those test microorganisms which are sensitive towards the phytoextracts used in present study were prepared by transferring a loop of culture into sterile nutrient and potato 
dextrose broth and incubated at $37 \mathrm{o}^{\circ}$ for $24-48$ hours. A loop full was taken from these broths and seeded onto sterile nutrient and potato dextrose agar plates through sterile cotton swab to develop diffused heavy lawn culture. The well diffusion method was used to determine the antimicrobial activity of methanolic extract prepared from the leaves of Lagerstroemia parviflora using standard procedure 34 . There were 3 concentration used which are 25 , 50 and $100 \mathrm{mg} / \mathrm{ml}$ for extracted phytochemicals in antibiogram studies. It's essential feature is the placing of wells with the antibiotics on the surfaces of agar immediately after inoculation with the organism tested. Undiluted overnight broth cultures should never be used as an inoculums. The plates were incubated at $37^{\circ} \mathrm{C}$ for $24 \mathrm{hr}$. and then examined for clear zones of inhibition around the wells impregnated with particular concentration of drug.

\section{RESULTS AND DISCUSSION}

\section{Results of antioxidant activity using DPPH method}

The effect of antioxidant on DPPH is believed to be due to their hydrogen-donating ability. The DPPH assay measures the antioxidant activity of water soluble phenolics. Table 1 and Figure 1 shows the dose-response curve of DPPH radical scavenging activity of the different methanolic extract of Lagerstroemia parviflora. It was observed that the methanol extract showed IC 50 value of $76.05 \mu \mathrm{g} / \mathrm{ml}$ as compare to standard ascorbic acid $14.66 \mu \mathrm{g} / \mathrm{ml}$. It was evident that the extracts showed proton-donating ability and this could serve as free radical inhibitors or scavengers, acting possibly as primary antioxidants. Thus the methanol extract of this plant possesses the strongest ability to scavenge DPPH radical.

Table 1: \% Inhibition of ascorbic acid and methanolic extract of Lagerstroemia parviflora (Leaves)

\begin{tabular}{|c|c|c|c|}
\hline \multirow{2}{*}{$\begin{array}{c}\text { S. No. } \\
(\mu \mathrm{g} / \mathbf{m l})\end{array}$} & \begin{tabular}{c} 
Concentration \\
\cline { 2 - 4 }
\end{tabular} & Ascorbic acid & Methanolic extract \\
\cline { 2 - 4 } & 10 & 38.16 & 30.25 \\
\hline 2 & 20 & 47.58 & 41.66 \\
\hline 3 & 40 & 54.91 & 48.19 \\
\hline 4 & 60 & 70.24 & 50.87 \\
\hline 5 & 80 & 79.83 & 54.74 \\
\hline 6 & 100 & 87.01 & 76.05 \\
\hline
\end{tabular}

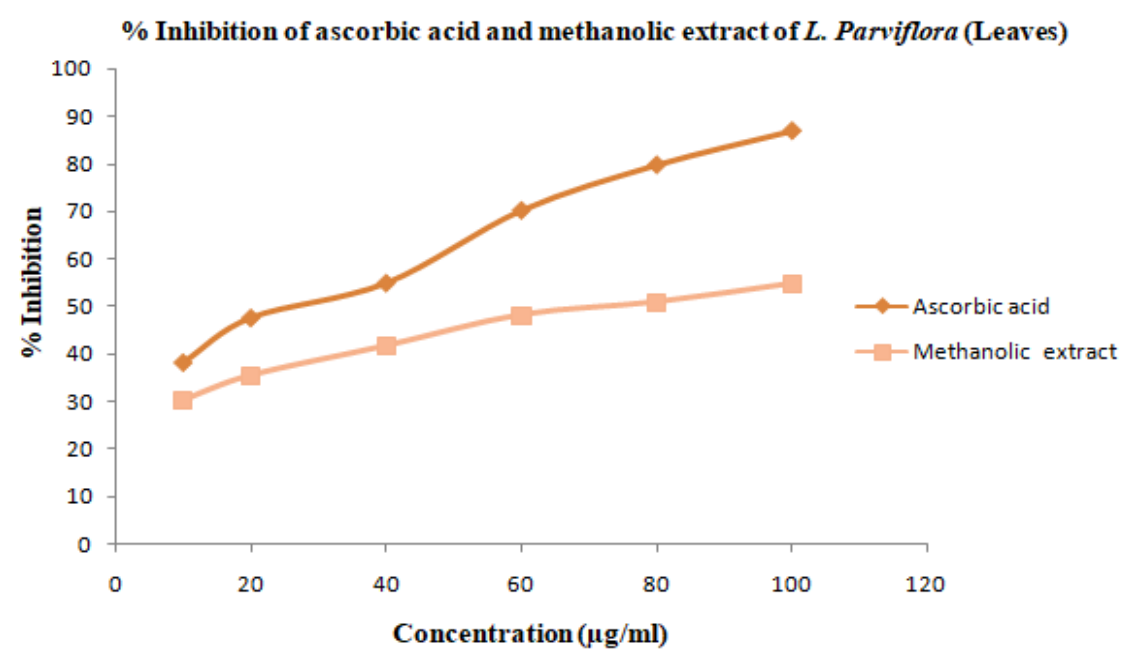

Figure 1: \% Inhibition of ascorbic acid and extract of Lagerstroemia parviflora using DPPH method

\section{Results of antimicrobial activity of methanolic extract of Lagerstroemia parviflora}

A study of zone of inhibition against bacterial strains with leaves extracts of Lagerstroemia parviflora revealed that all bacteria subjected to cold water extract showed zone of inhibition against Staphylococcus aureus, Salmonella bongori and Aspergillus niger Table 2, 3 and 4. The results of present study observed variation in antibacterial activities of the leaves extracts of Lagerstroemia parviflora to inhibit selected bacteria in vitro. However higher antimicrobial activity of
Lagerstroemia parviflora was seen with increase in concentration $(25-100 \mathrm{mg} / \mathrm{ml})$. The leaves extracts of Lagerstroemia parviflora exhibited potential antibacterial activity against Staphylococcus aureus $(10 \pm 0.47,14 \pm 0.74$ and 18 \pm 0.74$)$, Salmonella bongori $(12 \pm 0.35,14 \pm 0.6$ and $17 \pm 0.65)$ and Aspergillus niger $(7 \pm 0.74,10 \pm 0.5$ and $11 \pm 0.94$ ) at the concentration level of $25-100 \mathrm{mg} / \mathrm{ml}$. The Results of antimicrobial activity of extract showd more effectiveness against both the selected bacteria (Staphylococcus aureus and Salmonella bongori) found less effective against fungus (Aspergillus niger). 
Table 2: Results of sensitivity of methanolic extract of Lagerstroemia parviflora

\begin{tabular}{|c|c|c|c|}
\hline S. No. & $\begin{array}{c}\text { Microbes } \\
\text { Codes }\end{array}$ & Microbial Strains & Sensitivity \\
\hline 1. & Bact-1 & Staphylococcus aureus & Yes \\
\hline 2. & Bact-2 & Salmonella bongori & Yes \\
\hline 3. & Fungus-1 & Aspergillus niger & Yes \\
\hline
\end{tabular}

Table 3: Antimicrobial activity of standard drug against selected microbes

\begin{tabular}{|c|c|c|c|c|c|}
\hline S. No & Name of drug & Microbes & \multicolumn{3}{|c|}{ Zone of Inhibition (mm) } \\
\cline { 3 - 5 } & & & $\mathbf{1 0} \mathbf{\mu g} / \mathbf{m l}$ & $\mathbf{2 0} \mathbf{~} \mathbf{g} / \mathbf{m l}$ & $\mathbf{3 0} \boldsymbol{\mu g} / \mathbf{m l}$ \\
\hline 1. & Ciprofloxacin & Staphylococcus aureus & $23 \pm 0.47$ & $25 \pm 0.5$ & $27 \pm 0.94$ \\
\cline { 3 - 5 } & & Salmonella bongori & $16 \pm 0.5$ & $22 \pm 0.86$ & $24 \pm 0.57$ \\
\hline 2. & Fluconazole & Aspergillus niger & $7 \pm 0.74$ & $10 \pm 0.5$ & $11 \pm 0.94$ \\
\hline
\end{tabular}

Table 4: Antimicrobial activity of methanolic extract of Lagerstroemia parviflora against selected microbes

\begin{tabular}{|c|c|c|c|c|}
\hline \multirow[t]{3}{*}{ S. No. } & \multirow[t]{3}{*}{ Name of microbes } & \multicolumn{3}{|c|}{ Zone of inhibition } \\
\hline & & \multicolumn{3}{|c|}{ Methanolic extract } \\
\hline & & $25 \mathrm{mg} / \mathrm{ml}$ & $50 \mathrm{mg} / \mathrm{ml}$ & $100 \mathrm{mg} / \mathrm{ml}$ \\
\hline 1. & Staphylococcus aureus & $20 \pm 0.2$ & $21 \pm 0.1$ & $23 \pm 0.1$ \\
\hline 2. & Salmonella bongori & $9 \pm 0.3$ & $12 \pm 0.1$ & $15 \pm 0.5$ \\
\hline 3. & Aspergillus niger & $7 \pm 0.1$ & $9 \pm 0.1$ & $11 \pm 0.2$ \\
\hline
\end{tabular}

\section{CONCLUSION}

The results of the present work indicated that the hydroalcoholic extract of Lagerstroemia parviflora leaves is a potential source of natural antioxidants and significantly inhibit free radicals by dose-dependently and also showed better antibacterial activity. Hence, from the overall results, finally it was concluded that the formulated herbal gels have significant antimicrobial properties and hence will be better, safe and effective than allopathic medications.

\section{REFERENCES}

1. Candan F, Unlu M, Tepe B, Daferera D, Polissiou M, Sökmen A, Akpulat $\mathrm{H}$, Antioxidant and antimicrobial activity of the essential oil and methanol extracts of Achillea millefolium subsp. millefolium Afan. (Asteraceae), Journal of Ethnopharmacology, 2003; 87:215-220.

2. Zhu KX, Lian CX, Guo XN, Peng W, Zhou HM, Antioxidant activities and total phenolic contents of various extracts from defatted wheat germ, Food Chemistry, 2011; 126:1122-1126.

3. Spacil Z, Novakova L, Solich P, Analysis of phenolic compounds by high performance liquid chromatography and ultra-performance liquid chromatography, Talanta, 2008; 76:189-199.

4. Haila K, Effects of carotenoids and carotenoid-tocopherol interaction on lipid oxidation in vitro, Thesis, University of Helsinki, Helsinki, 1999.

5. Fukumoto LR, Mazza,Assessing G, antioxidant and prooxidant activities of phenolic compounds,Journal of Agricultural and Food Chemistry, 2000; 48:3597-35604.

6. Kitts DD, An evaluation of the multiple effects of the antioxidant vitamins, Trends in Food Science \& Technology, 1997; 8:198-203

7. Wall J, Antioxidants in prevention ofreperfusion damage of vascularendothelium,Pharmacology, 2000; 1:67-71.

8. Aquino R, Morelli S, Tomaino A, Pellegrino M, Saija A, Grumetto L, Puglia C, Ventura D, Bonina F, Grumetto L, Antioxidant and photoprotective activity of a crude extract of
Culcitium reflexum $\mathrm{H}$. B. K. Leaves and their major flavonoids, Journal of Ethnopharmacology, 2002; 79:183- 191.

9. Silva BA, Malva JO, Dias ACP, St. John's Wort (Hypericum perforatum) extracts and isolated phenolic compounds are effective antioxidants in several in vitro models of oxidative stress, Food Chemistry, 2008; 110:611-619.

10. Ito $\mathrm{N}$, Fukushina $\mathrm{S}$, Tsuda $\mathrm{H}$, Carcinogenicity and modification of the carcinogenic response by BHA, BHT and other antioxidants, CRC Critical Review in Toxicology, 1985; 15:109-115.

11. Canadanovic-Brunet JM, Djilas DM, Cetkovic GS, Tumbas VT, Mandić AI, Canadanovic VM, Antioxidant activities of different Teucrium montanum L. extracts,International Journal of Food Science \& Technology, 2006; 41:667-673.

12. Djilas SM, Canadanovic-Brunet JM, Cetkovic GS, Tumbas VT, Antioxidative activity of some herbs and species - review of ESR studies, In P. S. Gill, A. M. Webb, G. A. RutledgeEds., Magnetic resonance in Food Science, Belton, Cambridge, 2003 pp. $110-120$.

13. ANostro N, Germano MP, D'Angelo V, Marino A, Cannetelli MA Extraction methods and bioautography for evaluetion of medicinal plant antimicrobial activity, Letters in Applied Microbiology, 2000; 30:379-384.

14. Marimuthu P, Wu CL, Chang HT, Chang ST, Antioxidant activity of the ethanolic extract from the bark of Chamaecyparisobtusa var. Formosana, Journal of the Science of Food and Agriculture, 2008; 88:1400-1405.

15. Proestos C, Boziaris IS, Nychas GJE, Komaitis M, Analysis of flavonoids and phenolic acids in Greek aromatic plants: Investigation of their antioxidant capacity and antimicrobial activity, Food Chemistry, 2006; 95:664- 671.

16. Papadopoulou C, Soulti K, Roussis IG, Potential antimicrobial activity of red and white wine phenolic extracts against strains of Staphylococcus aureus, Escherichia coli and Candida albicans,Food Technology and Biotechnology, 2005; 43:41-46.

17. Obame LC, Koudou J, Kumulungui BS, Bassolé IHN, Edou P, Ouattara AS, Traoré AS, Antioxidant and antimicrobial activities of Canarium schweinfurthii Engl. Essential oil from 
Centrafrican Republic, African Journal of Biotechnology, 2007; 6:2319-2323.

18. Basile A, Sorbo S, Spadaro V, Bruno M, Maggio A, Faraone N, Rosselli S, Antimicrobial and antioxidant activities of coumarins from the roots of Ferulago campestris (Apiaceae), Molecules, 2009; 14:939-952.

19. Saddiqe Z, Naeem I, Maimoona A, A review of the antibacterial activity of Hypericum perforatum L, Journal of Ethnopharmacology, 2010; 131:511-521.

20. Recio MC, RíosJL, Villar A, A review of some antimicrobial compounds isolated from medicinal plants reported in the literature 1978-1988, Phytotheraphy Research, 1989; 3:117125.

21. Rauha JP, Remes S, Heinonen M, Hopia A, Kahkonen M, KujalaT, Vuorela KPH, Vuorela P, Antimicrobial effects of Finnish plant extracts containing flavonoids and other phenolic compounds, International Journal of Food Microbiology, 2000; 56:3-12.

22. Bisignano G, Tomaino A, Lo Cascio R, Crisafi G, Uccella N, Saija A, On the in vitro antimicrobial activity of oleuropein and hydroxytyrosol, Journal of Pharmacy and Pharmacology, 1999; 51:971-974.

23. Chan MMY, Antimicrobial effect of resveratrol on dermatophytes and bacterial pathogens of the skin, Biochemical Pharmacology, 2002; 63:99-104.

24. Wen AM, Delaquis P, Stanich K, Toivonen P, Antilisterial activity of selected phenolic acids, Food Microbiology, 2003; 20:305-311.

25. Date AA, Naik B, Nagarsenker MS. Novel drug delivery systems: potential in improving topical delivery of anti-acne agent. Skin Pharmacol Physiol. 2006; 19:2-16.
26. Collier CN, Harper JC, Cafardi JA. The prevalence of acne in adults 20 years and older. J Am Acad Dermatol. 2008; 58:5659.

27. Gollnick H, Cunliffe W, Berson D, Dreno B, Finlay A, Leyden JJ, Shalita AR, Thiboutot D. Management of acne: a report from a global alliance to improve outcomes in Acne. J Am Acad Dermatol. 2003; 49:S1-S37.

28. Gollnick H., Cunliffe W., Berson D., Dreno B.A., Leyden J., Shalita A. and Thiboutot D. Finlay Management of Acne: A Report from a Global Alliance to Improve Outcomes in Acne. $J$ Am Acad Dermatol. 2003; 49:S1-S37.

29. Krautheim A. and Gollnick H. Transdermal penetration of topical drugs used in the treatment of acne. Clin Pharmacokinet. 2003; 42:1287-1304.

30. Date A.A., Naik B. and Nagarsenkar M.S. Novel Drug Delivery Systems: Potential in Improving Topical Delivery of Antiacne agents. Skin Pharmacol Physiol. 2006; 19:2-16.

31. Schofer T., Nienhaus A., Vieluf D., Berger J. and Ring J.: Epidemiology of Acne in the General Population: The Risk of Smoking. Br J Dermatol. 2001; 145:100-104.

32. Bassett IB, Pannowitz DL, Barnetson RSC. A comparative study of teatree oil versus benzoyl peroxide in the treatment of acne. Med J Aus.1990; 153:455-458.

33. Olufunmiso, Olajuyigbe, O. and Afolayan, Anthony, J. Phenolic Content and antioxidant property of the bark extract of Ziziphus mucronata wild. Subsp. Mucronata wild, BMC, Complementary and alternative medicine. 2011; 11:130.

34. Bauer AW, Kirby WM, Sherris JC, Turck M. Antibiotic susceptibility testing by a standardized single disk method. Am J Clin Pathol. 1966; 45(4):493-496. 